\title{
Vascular Neuro-ophthalmology
}

Cédric Lamirel, MD ${ }^{\mathrm{a}, 1}$, Nancy J. Newman, $\mathbf{M D}^{\mathrm{b}, 2}$, and Valérie Biousse, $\mathbf{M D}^{\mathrm{c}, 3}$ ${ }^{a} F e l l o w$. Neuro-Ophthalmology Unit. Emory Eye Center. Atlanta, GA, USA

bLeo Delle Jolley Professor of Ophthalmology. Professor of Ophthalmology, Neurology and Neurological Surgery. Emory University School of Medicine, Atlanta, GA. USA

${ }^{c}$ Cyrus H. Stoner Professor of Ophthalmology. Professor of Ophthalmology, Neurology and Neurological Surgery. Emory University School of Medicine, Atlanta, GA. USA

\section{Keywords}

stroke; ischemia; carotid artery; vertebra-basilar circulation; retinopathy

\section{Introduction}

Vascular neuro-ophthalmology includes visual symptoms and signs found in stroke patients as well as numerous primary vascular disorders involving the eye and the optic nerves. The clinical presentation varies depending on the type of vessel involved (arteries versus veins), the type of stroke (ischemic or hemorrhagic), and the size of the arteries involved (large versus small artery disease).

The blood supply to the eye is mostly provided by branches of the ophthalmic artery, which is a branch of the internal carotid artery (ICA) (Fig. 1A). This is why many patients with cerebral ischemia in the territory of the anterior circulation may present with ipsilateral visual changes. The posterior circulation provides the blood supply to the occipital lobes and posterior fossa; hence binocular visual loss or abnormal extraocular movements are common with vascular diseases affecting the posterior circulation. In addition, a number of ocular vascular disorders are associated with specific neurologic manifestations and numerous systemic inflammatory diseases or hypercoaguable states can affect the eyes and the brain simultaneously.

\section{Large-artery disease}

Anterior and posterior large-artery circulation ischemia is often associated with visual symptoms and signs which may precede a cerebral infarction.

1.1. Anterior circulation (carotid artery disease)—A variety of transient and permanent visual symptoms and signs may develop in patients with carotid artery disease. The hallmark of most of these disturbances is their monocular nature, ispilateral to the affected ICA. However, contralateral homonymous visual field defects, bitemporal visual

\footnotetext{
${ }^{3}$ Corresponding author : Neuro-Ophthalmology Unit. Emory Eye Center 1365-B Clifton Road, NE. Atlanta, GA 30322. USA ybiouss@emory.edu Tel: 404778 5360. Fax: 4047784849.

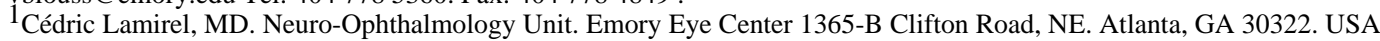
clamire@emory.edu Tel: 4047785360 Fax: 4047784849

${ }^{2}$ Nancy J Newman, MD. Neuro-Ophthalmology Unit. Emory Eye Center 1365-B Clifton Road, NE. Atlanta, GA 30322. USA ophtnjn@emory.edu Tel: 4047785360 Fax: 4047784849
} 
field defects, and bilateral simultaneous visual loss may result from diseased carotid arteries and their branches, particularly when the disease is bilateral.

1.1.1.Transient monocular visual loss ("amaurosis fugax"): This is the most common ophthalmologic symptom of disease of the ICA. The term "amaurosis fugax" is often used to describe any cause of transient monocular visual loss and should be abandoned [1]. The evaluation and management of patients with transient visual loss are detailed in chapter 3. It is important to emphasize that there are numerous nonvascular causes of transient monocular visual loss which require an emergent detailed ocular examination; therefore an ophthalmic consultation should be obtained before launching an extensive work up for presumed vascular transient monocular visual loss [2]. Multiple episodes of transient visual loss or painful transient visual loss in the elderly should raise the possibility of giant cell arteritis.

1.1.2. Permanent visual loss: Partial or complete monocular loss of vision may occur in patients with carotid artery disease, usually in the ipsilateral eye. This results most often from a central retinal artery occlusion (CRAO) or from one or multiple branch retinal artery occlusions (BRAO). In such cases, an embolus may be seen in the affected vessels. Other causes of permanent monocular visual loss in patients with carotid artery disease include venous stasis retinopathy, and the ocular ischemic syndrome [3]. Ischemic optic neuropathy, anterior or posterior, results from small vessel disease (Fig. 1B) and is usually not associated with large artery disease [4], explaining why carotid artery evaluation is not usually indicated in patients with classic anterior ischemic optic neuropathy.

The second major visual sign of carotid occlusive disease is a partial or complete contralateral homonymous hemianopic visual field defect. This is most often caused by occlusion of branches of the middle cerebral artery, but it may result from occlusion of the anterior choroidal artery or some of its branches to the optic tract and lateral geniculate body. Rarely, patients with carotid occlusive disease have severe visual deficits caused by a combination of monocular visual loss from ocular circulation insufficiency and contralateral homonymous field loss from damage to the ipsilateral post-chiasmal visual sensory pathway.

1.1.2.1. Central and branch retinal artery occlusion: Patients who experience a retinal infarction usually complain of acute loss of visual acuity, visual field, or both. Permanent visual loss may be preceded by episodes of transient monocular visual loss. Patients with a CRAO almost always have extremely poor visual acuity in the affected eye. Acute CRAO is characterized by diffuse pale swelling of the retina, a macular "cherry red" spot, and attenuation of the retinal vessels (Fig. 2) [5]. Within a few weeks, the retinal vessels often recanalize and the retina has an almost normal appearance; however, the optic disc becomes pale (Fig. 3) [5]. Emboli are seen in up to $40 \%$ of central retinal artery occlusions and in a majority of branch artery occlusions (Fig. 4) [5,6,7]. The most common emboli that occlude retinal arterioles are made of cholesterol, fibrin-platelets, and calcium fragments (Table 1).

Carotid artery disease is responsible for the majority of retinal infarctions. In patients with embolic retinal infarction who have a normal ICA, the aortic arch or the heart are the most likely sources of emboli (8). The prognosis of CRAO is poor and treatment is limited. None of the "classic" treatments often offered by ophthalmologists (including ocular massage, anterior chamber paracenthesis, etc...) are proven to be useful and we do not recommend them routinely. Selective intra-arterial thrombolysis (directly into the ophthalmic artery) or intra-venous thrombolysis are sometimes performed in specialized centers, but remain debated until a clinical trial shows their efficacy and safety $[9,10]$. 
1.1.2.2. Ophthalmic artery occlusion: Ophthalmic artery occlusion usually results from large emboli in the ophthalmic artery. The visual loss is profound and the prognosis poor. Funduscopic examination shows extensive retinal ischemia which appears white and edematous, often with hemorrhages and with poor or no retinal artery filling, as well as disc edema. Since the choroidal circulation is also compromised, there is no "cherry red" spot (Fig. 5).

1.1.2.3. Homonymous visual field defects: Ischemia in the anterior circulation (carotid territory) may be associated with a contralateral homonymous hemianopia when there is a lesion of the optic tract, lateral geniculate body, or anterior optic radiations.

Damage to the optic tract produces a contralateral homonymous hemianopia associated with a relative afferent pupillary defect on the side of the hemianopia, and subsequent optic nerve atrophy (because the axons of the optic tract originate in the ganglion cell bodies of the retina) [11].Lesions of the lateral geniculate body may produce a homonymous sectoranopia because of its unique blood supply. Lesions of the anterior optic radiations typically produce a contralateral homonymous hemianopia, usually in association with other neurologic symptoms or signs [3].

\subsubsection{Venous stasis retinopathy and ocular ischemic syndrome: Venous stasis} retinopathy - also called hypotensive retinopathy — is caused by severe carotid obstructive disease and poor collateral circulation. The retinopathy is characterized by insidious onset, dilated and tortuous retinal veins, peripheral microaneurysms, and dot-blot hemorrhages in the midperipheral retina (Fig. 6). Patients with this condition complain primarily of generalized blurred vision in the affected eye or may be asymptomatic. Symptoms of carotid insufficiency, such as transient monocular visual loss, decreased vision after exposure to bright light, and orbital pain are common. Venous stasis retinopathy may occur as part of the ocular ischemic syndrome or in isolation. It is found in up to 4-18\% of patients with carotid occlusive disease, and is often asymptomatic $[12,13,14]$. Venous stasis retinopathy usually resolves spontaneously if arterial patency can be restored [13]. In many cases, however, there is persistent visual dysfunction from irreversible retinal ischemic changes. If ocular perfusion cannot be improved, the affected eye may develop neovascularization of the iris and optic disc as well as other signs of ocular ischemia. In such cases, ablation of hypoxic retinal tissue by panretinal photocoagulation may prevent progression of the condition and may actually produce regression of neovascularization $[14,15]$.

The ocular ischemic syndrome (also called ischemic ocular inflammation or chronic ocular ischemia) is a progressive disorder resulting from chronic hypoperfusion of the eye $[14,16]$. Patients describe blurry vision that may be transient or persistent. Visual loss is typically insidious and slowly progressive. Some patients describe positive after-images when exposed to bright light. The affected eye is often red, with episcleral vascular dilation [15]. The ocular fundus shows venous stasis retinopathy, sometimes associated with neovascularization. Some patients will have severe ocular or peri-orbital pain which is often improved when they lie down [16]. In eyes with persistent hypoperfusion, neovascularization of the iris, retina, optic disc, and anterior chamber angle develop. Other signs of ocular ischemia include corneal edema, uveitis, cataract formation, and a dilated and poorly reactive pupil [14]. The visual prognosis is extremely poor. Although early retinopathy may resolve spontaneously with the development of collateral circulation, severe loss of vision is almost always irreversible once tissue infarction occurs [14,15].

The treatment of the ocular ischemic syndrome is aimed at preservation and improvement of visual function and treatment of the underlying process $[14,15]$. The first requires a relative decrease in the oxygen requirements of the eye, thus reducing the drive for 
neovascularization. This is usually accomplished by ablation of retinal tissue by laser panretinal photocoagulation or peripheral retinal cryotherapy. When severe carotid artery stenosis is the underlying condition, endarterectomy or carotid stenting may be used to reestablish flow. When, as is usually the case, the artery is occluded, a superficial temporal artery to middle cerebral artery bypass procedure may be beneficial if the external carotid artery is patent. When the internal and external carotid arteries are occluded, some form of revascularization of the external carotid artery may be of some benefit. However, revascularization procedures have been associated with ocular complications such as retinal or vitreal hemorrhages and elevated intraocular pressure. Moreover, patients with such severe carotid disease and poor collateral circulation often have a high surgical risk. No therapy is clearly effective in reversing the ocular ischemic syndrome.

1.1.3.Horner syndrome: Although it is more common in carotid artery dissections, Horner syndrome may occur in patients with atherosclerotic carotid artery disease (Fig. 7) [17]. Most such patients have complete occlusion of the ICA, and the Horner syndrome is associated with other neurological symptoms and signs of carotid artery disease. Horner syndrome occurring in patients with occlusion of the internal carotid artery is almost always postganglionic (third order) (see chapter 7).

1.1.4. Ocular motor nerve paresis: Exceptionally, patients with acute occlusion or severe ICA stenosis may develop one or more ocular motor nerve pareses on the side of the occlusion, either in isolation or with signs of ocular ischemia [18]. In some cases of isolated ocular motor nerve palsy, ischemia of the nerve probably results from reduction of blood flow through mesencephalic branches of the anterior choroidal artery. In other cases, blood supply to the cranial nerves themselves, which originates from branches of the ICA, may be compromised $[3,19]$.

1.1.5.Referred pain: Isolated ocular pain may be a symptom of carotid occlusive disease, even without other symptoms and signs of vascular disease. It is usually a referred pain resulting from ischemia or compression of the trigeminal branches. It may also be part of the ocular ischemic syndrome [3].

1.2.Posterior circulation-The vertebrobasilar system supports the neural components of the entire brainstem ocular motor system as well as those of the posterior visual sensory pathways and visual cortex. For this reason, ocular motor and visual symptoms and signs play a major role in the diagnosis of vascular disease in the vertebrobasilar system.

1.2.1.Transient binocular visual loss: Episodes of transient binocular visual loss are common in vertebrobasilar ischemia. The visual loss is always bilateral, with both eyes being affected simultaneously and symmetrically [3,20.21,22]. The change in vision may be described as a sudden "grayout of vision," "a sensation of looking through fog or smoke," or "the feeling that someone has turned down the lights." Most attacks of blurred vision that result from vertebrobasilar ischemia last less than a minute. Attacks of longer duration may be accompanied by flickering, flashing "stars" of silvery light in a homonymous or altitudinal field of vision. They may occur alone or in combination with other transient symptoms in the vertebrobasilar territory. The episodes of blurred vision that occur in patients with occipital ischemia must be differentiated from other causes of transient or permanent visual loss. Transient, complete $90-180^{\circ}$ inversion of the visual image occasionally occurs.

1.2.2. Homonymous visual field defects: An isolated homonymous visual field defect of sudden onset is the hallmark of a vascular lesion in the occipital lobe (Fig. 8). Such a lesion 
is usually the result of infarction in the territory supplied by the posterior cerebral artery (PCA) (Table 2). The field defect may be complete or incomplete, but when it is incomplete or scotomatous, it is usually congruous. When there is a complete homonymous hemianopia, macular sparing is common, and the occipital pole is usually spared. Patients with a homonymous visual field defect caused by ischemia in the PCA territory have normal visual acuity. When both occipital lobes are infarcted, visual acuity is usually severely impaired but the amount of visual loss is symmetric in both eyes (Fig. 9). In some cases of occipital lobe infarction, the anterior portion of the lobe is unaffected, resulting in sparing of part or all of the peripheral $30^{\circ}$ of the contralateral, monocular temporal field - the temporal crescent. Symptoms of PCA occlusion usually occur without warning. The patient may have a slight sensation of dizziness or light-headedness and then become aware of a homonymous visual field defect. Some patients initially experience complete blindness, with vision returning in the ipsilateral homonymous visual field within minutes. Pain in the ipsilateral eye or over the ipsilateral brow (contralateral to the hemianopia) is an important although inconstant symptom in such patients [23]. This pain is referred from the tentorial branches of the trigeminal nerve.

1.2.3.Disorders of higher cortical function: A number of syndromes described by patients as "difficulty seeing" or "difficulty reading" may result from cerebral ischemia $[3,11]$.

Alexia without agraphia results from infarction of the left occipital lobe and disruption of the left ventral visual association cortex and its outflow tracts to the left angular gyrus, thus interrupting input from the right occipital area to the language verbal association area. Patients can usually name individual letters or numbers, but they cannot read words or phrases. Although they are able to write, they cannot read it back moments later. Patients in whom there is infarction of the left occipital lobe and the splenium of the corpus callosum have no visual information to send to the language center from the left occipital lobe, and information from the right occipital lobe cannot be transmitted across to the left language center via the corpus callosum.

Gerstmann syndrome results from infarction of the left angular gyrus secondary to an occlusion of the left PCA. Patients have difficulty telling right from left, difficulty in naming digits on the patient's own or another's hand, constructional dyspraxia, agraphia, and difficulty calculating.

Associative visual agnosia is present in some patients with a left PCA occlusion. It consists of difficulty understanding the nature and use of objects presented visually. However, they can trace with fingers, and they can copy an object presented in the hand and explored by touch or verbally described by the examiner.

Prosopagnosia results from occlusion of the right PCA. Patients with this condition have difficulty recognizing familiar faces. The patients may also have difficulty revisualizing to themselves what a given object or person should look like, and their dreams are often devoid of visual imagery.

Visual neglect is much more common after occlusion of the right posterior cerebral artery with infarction of the right parietal lobe than it is after occlusion of the left posterior cerebral artery.

Cerebral blindness occurs with bilateral PCA occlusions. Patients with this syndrome may have premonitory episodes of bilateral visual blurring or focal brainstem ischemia before they develop acute, bilateral, simultaneous visual loss caused by bilateral simultaneous homonymous hemianopia. Many cases of cortical blindness are caused by basilar artery thrombosis. The pupils and fundus examination are normal. Many of the patients experience 
photopsias or formed visual hallucinations while they are totally blind. Denial of blindness, known as Anton's syndrome, is common. Bilateral occipital lobe infarction can produce decreased central visual acuity in both eyes without any obvious hemianopic defect. The loss of central vision probably results from generalized ischemia of the occipital lobes and is symmetric in both eyes, unless there is an associated unilateral or asymmetric ocular disease.

Balint's syndrome can occur in patients who experience bilateral simultaneous or sequential PCA occlusions, although it is most common after bilateral watershed infarctions between the PCA and MCA territories, primarily damaging the parieto-occipital visual associative areas. Balint's syndrome occurs much more frequently after bilateral watershed infarctions of the parieto-occipital regions from systemic hypotension than from thrombo-embolic carotid or vertebrobasilar disease. Patients with this syndrome present with a triad of "psychic paralysis of visual fixation," "optic ataxia," and visuospatial disorientation. Patients with Balint's syndrome have a variety of abnormalities of fixation and tracking. They have great difficulty locating a stationary object in space, although they can maintain fixation on the object once they locate it. They can track a moving target, but if the target begins to move rapidly, it is lost and cannot be relocated.

Simultagnosia may develop in patients with bilateral superior occipital lobe strokes. Such patients complain of piecemeal perception of the visual environment wherein objects may look fragmented or even appear to vanish from direct view. Simultagnosia is caused by a defect in visual attention that results in an inability to sustain visuospatial processing across simultaneous elements in an array. Simultagnosia, like Balint's syndrome and other higher disorders of visual processing and attention, occurs much more frequently after systemic hypotension with watershed infarctions than from occlusion of the PCAs. Common causes include cardiac arrest and intraoperative hypotension.

Achromatopsia occurs in association with prosopagnosia when occipital lobe infarction is limited to the lower banks of the calcarine fissures on both sides.

1.2.4.Visual hallucinations: Formed visual hallucinations may be produced by vertebrobasilar ischemia. These hallucinations, which may last 30 minutes or more, may be associated with decreased consciousness, but they usually occur in an otherwise alert patient who is aware that the visual images are not real. The hallucinations are generally restricted to a hemianopic field, and they are often complex. Some of the visual hallucinations that occur in patients with posterior cerebral artery occlusion are palinoptic, with the hallucinations consisting of recently or previously seen images [3].

1.2.5.Diplopia: Transient binocular horizontal or vertical diplopia is a common manifestation of vertebrobasilar ischemia. The diplopia may result from transient ischemia of the ocular motor nerves or their nuclei (ocular motor nerve paresis) or from transient ischemia to supranuclear or intemuclear ocular motor pathways (skew deviation, internuclear ophthalmoplegia, gaze paresis). In most cases, the diplopia is not isolated and the patient has other neurologic symptoms suggesting vertebrobasilar ischemia $[24,25,26,27,28,29]$.

Persistent disturbances of eye movements are extremely common in patients with vertebrobasilar ischemia. Ocular motor nerve paresis, internuclear ophthalmoplegia, supranuclear deficits and nystagmus develop based on the anatomical location of the lesion. Nystagmus produces oscillopsia which is often described by the patients as ““'jumping of vision." 


\section{Small-artery disease}

2.1.Arteritis-Both infectious and noninfectious inflammation affecting the central nervous system can produce visual symptoms. In some vasculitides with a predilection for large arteries, such as Takayasu's arteritis, ocular ischemia is common. Most often, vasculitis produces retinal vasculitis with retinal vascular occlusions and visual loss, often associated with ocular inflammation (uveitis) (Fig. 10) [3].

Giant cell arteritis should be considered in all patients over 50 years-old presenting with acute optic nerve or retinal ischemia [30]. Permanent visual loss is common in giant cell arteritis, and is often preceded by transient monocular visual loss (see chapter 8 ).

2.2.Susac syndrome-Susac syndrome describes young patients with multiple bilateral branch retinal arterial occlusions, hearing loss, and neurologic symptoms suggestive of a brain microangiopathy [31]. It classically occurs in young women but can affect men. Affected patients have recurrent multiple branch retinal occlusions that are most often bilateral, progressive hearing loss, and various neurologic presentations including psychiatric changes and encephalopathy. The disease usually has a chronic relapsing course punctuated by frequent remissions and exacerbations [31].

Retinal fluorescein angiography classically shows retinal arterial wall hyperfluorescence, which is indicative of disease activity (Fig.11) Hearing loss primarily involves low and medium frequencies, and is best demonstrated by audiogram. It is believed to result from cochlear damage caused by occlusions of the cochlear end arterioles. Encephalopathy varies in severity from mild memory loss and personality changes to severe cognitive dysfunction, confusion, psychiatric disorders, seizures, and focal neurologic symptoms and signs. The brain involvement in Susac syndrome is usually the most severe part of the disease and is frequently very debilitating.

Electroencephalograms usually show diffuse slowing. Cerebrospinal fluid examination may be normal or show a variable degree of leukocytosis (lymphocytes), with elevation of protein. The neuroimaging modality of choice is the brain MRI, which typically shows multiple enhancing small lesions in both the white and gray matter, with classic involvement of the corpus callosum (an otherwise unusual location for vascular disease) [32]. The MRA is normal, but catheter angiography has shown evidence of vasculopathy in some patients. In a few cases, brain biopsy was performed and showed microinfarcts with some minimal perivascular lymphocytic infiltration, but no true vasculitis.

Because of the spontaneously remitting — relapsing course of Susac syndrome, and the small number of cases reported, it is difficult to assess the efficacy of the various treatments that have been tried. Most patients receive steroids, immunosuppressive agents, and antiplatelet/ antithrombotic therapy until the disease becomes clinically inactive $[31,33]$.

2.3.Hereditary retinopathies-A number of rare hereditary retinopathies are associated with central nervous system abnormalities. Recent genetic characterization of three of these syndromes has shown that there is an overlap among these entities (Table 3) [34].

\subsection{Miscellaneous angiopathies of the central nervous system with ocular} manifestations-A variety of other systemic disorders producing strokes may be associated with ocular abnormalities (Table 4). Most are inherited disorders, and ophthalmic manifestations may reveal the angiopathy $[3,11]$.

2.5.Hypertensive encephalopathy-Patients with systemic hypertension may develop a severe encephalopathy often associated with reversible visual loss (also called posterior 
reversible encephalopathy syndrome) (Fig. 9) [35,36]. Hypertensive retinopathy may also be present bilaterally and does not always correlate with the severity of the hypertensive encephalopathy. There may be associated optic nerve head edema which may mimic that of raised intracranial pressure (Fig. 12).

2.6.Ischemic optic neuropathies-Most vascular diseases involving the optic nerve fall under the category of anterior and posterior ischemic optic neuropathies believed to be small vessel diseases [4]. These entities are discussed in chapter 5.

\subsection{Retinopathy and retinal vascular caliber and the risk of stroke and} coronary artery disease-Several studies have shown that retinal microvascular changes are related to clinical stroke, stroke mortality, coronary artery disease, cognitive changes, cerebral white matter changes detected by MRI, and cerebral atrophy $[37,38,39,40]$. In these studies, retinal vascular changes (generalized and focal narrowing of the retinal arterioles, arteriovenous nicking, micro- aneurysms) and retinopathy (cotton wool spots, retinal hemorrhages) were evaluated on fundus photographs $[37,38,39,40]$.

\section{Aneurysms, fistulas, and vascular malformations}

3.1.Aneurysms-The most common neuro-ophthalmic manifestations of intracranial aneurysms are secondary to a local mass effect on adjacent cranial nerves. The pulsatile process of the aneurysm may be as important as the direct mass effect [41]. Manifestations of the aneurysm depend on its location and its size. Aneurysms arising from the ophthalmic artery, the cavernous carotid artery, the anterior communicating artery, or the internal carotid artery can result in unilateral optic neuropathy or chiasmal visual field defects [42]. Rarely, a homonymous hemianopia can result from compression of the optic tract. Multiple ocular nerve palsies can result from an aneurysm involving the cavernous carotid artery. Posterior communicating artery aneurysms classically produce an isolated third nerve palsy, whereas isolated trochlear or abducens nerve palsies only rarely result from aneurysmal compression (see chapter 1) [43].

Aneurysmal rupture producing a subarachnoid hemorrhage may be associated with retinal, subhyaloid, and vitreal hemorrhages in one or both eyes (so called "Terson syndrome") (Fig. 13). The presumed mechanism is that of acute raised intracranial pressure with sudden elevation of ocular central venous pressure. Vision loss is variable but is not associated with a relative afferent pupillary defect unless the retina is detached. The diagnosis is often delayed in ICU patients who may not be aware of visual loss. Unless there is an associated retinal detachment, treatment is usually deferred and a vitrectomy is performed only if the hemorrhage does not resolve spontaneously $[42,43]$.

When an aneurysm arises from the cavernous carotid artery or from its branches in the cavernous sinus, rupture results in carotid-cavernous fistula, not subarachnoid hemorrhage.

3.2.Carotid-cavernous sinus fistula-Direct carotid-cavernous fistula results from direct communication of the cavernous carotid artery and the cavernous sinus with resultant high velocity of blood flow [44]. Direct carotid-cavernous fistulas can result from trauma or from rupture of a preexisting aneurysm of the cavernous carotid artery. Ocular manifestations are usually obvious and include proptosis, periorbital swelling, chemosis, dilation of the episcleral vessels, orbital bruit, ophthalmoplegia, elevated intraocular pressure, dilation or occlusion of the retinal veins and optic disc edema [45].

Dural carotid-cavernous sinus fistulas result from indirect communications between branches of the internal and external carotid arteries and the cavernous sinus. They are more common in middle aged and elderly woman. Neuro-ophthalmic manifestations depend on 
the blood flow velocity and vary from the full classical appearance of direct fistulas to isolated bruit, cranial nerve palsies, or simply a "red eye" (Fig. 14). Their diagnosis is therefore more difficult and is often delayed.

Orbital imaging with CT or MRI classically shows dilatation of the superior ophthalmic veins, enlargement of the extra-ocular muscles, or enlargement of the cavernous sinus (Fig. 14). Catheter angiography is still the best way to confirm a carotid cavernous fistula which can often be treated with an endovascular approach at the same time.

3.3.Arteriovenous malformations-Intracranial arteriovenous malformations may result in intraparenchymal hemorrhage, subarachnoid hemorrhage, seizures, or mass effect $[46,47]$. Occipital arteriovenous malformations can cause episodic visual symptoms mimicking the visual aura of migraine. Homonymous hemianopia is common in occipital lesions, most often as the result of bleeding or as a complication of treatment (Fig. 15). Posterior fossa arteriovenous malformations usually cause intermittent or permanent diplopia, often associated with other neurological signs. Orbital arteriovenous malformations produce an acute or subacute orbital syndrome, including proptosis, chemosis, ophthalmoplegia, visual loss, and elevation of the intraocular pressure.

Retinal arteriovenous malformations are rare. They are sometimes isolated or are associated with intracranial or facial arteriovenous malformations [48].

3.4.Cavernous hemangioma-Cavernous hemangiomas are most common in the posterior fossa and usually produce diplopia when they bleed [46]. Familial cavernous hemangiomas are often multiple and may be associated with grape-like appearing small retinal hemangiomas which are usually asymptomatic (Fig. 16).

\section{Venous disease}

4.1.Central and branch retinal vein occlusion-Central retinal vein occlusion (CRVO) is a common ocular disorder in elderly patients, often associated with atheromatous vascular risk factors [49]. Occlusion of the central retinal vein is presumed to result from compression by the central retinal artery within the optic nerve. Central retinal vein occlusion is also the most common ocular vascular occlusion associated with hypercoaguable states, whereas central retinal artery occlusion and ischemic optic neuropathy are very rarely associated with hypercoaguable states. Patients with CRVO complain of blurry vision, the severity of which depends on the severity of the CRVO and associated retinal ischemia. Funduscopic examination reveals diffusely spread retinal superficial hemorrhages, retinal and macular edema, dilated and tortuous veins, and optic disc edema (Fig. 17). Cotton-wool spots suggest associated retinal ischemia, indicating a worse visual prognosis. Neovascularization of the retina, optic disc, and iris predisposes the patient to intravitreous hemorrhage, traction retinal detachment and neovascular glaucoma. This disorder is primarily managed by the ophthalmologist and the goals of the treatment are to treat macular edema and prevent or treat neovascularization and its complications [50].

Branch retinal vein occlusions (BRVO) result from direct compression from a retinal branch artery sharing a common sheath at an arterio-venous crossing (Fig 18). The signs of vein occlusion are limited to the retinal area drained by the occluded branch vein. Vision loss depends on the localization of the occluded vein branch and the involvement or sparing of the macula; prognosis is usually much better than for CRVO [51].

4.2. Cerebral venous thrombosis-Cerebral infarction related to cerebral venous thrombosis may present with acute focal neurological signs, including homonymous hemianopia or cranial nerve palsies, usually in the setting of headaches or altered mental 
status [52,53]. Most neuro-ophthalmic manifestations of cerebral venous thrombosis, however, are related to increased intracranial pressure [54], and include papilledema and diplopia from uni- or bilateral sixth nerve palsies (Fig. 19). Diagnosis and management of cerebral venous thrombosis are detailed in chapter 2 .

Cavernous sinus thrombosis is extremely rare and produces acute painful proptosis with chemosis, ophthalmoplegia, venous stasis retinopathy and visual loss [55].

\section{Summary}

Cerebrovascular diseases are commonly associated with neuro-ophthalmologic symptoms or signs, which mostly depend on the type, the size and the location of the vessels involved, and the mechanism of the vascular lesion. Funduscopic examination allows direct visualization of the retinal circulation which shares many common characteristics with the cerebral microcirculation, and can be used as a marker of vascular disease

\section{Acknowledgments}

This work was supported in part by a departmental grant (Department of Ophthalmology) from Research to Prevent Blindness, Inc, New York, New York, and by core grant P30-EY06360 (Department of Ophthalmology) from the National Institute of Health, Bethesda, Maryland. Dr Newman is a recipient of a Research to Prevent Blindness Lew R. Wasserman Merit Award. Dr Lamirel is supported by Research Grants from Institut Servier (Paris, France), Fondation Planiol (Varennes, France) and the Philippe Foundation Inc. (New York, USA)

\section{References}

1. Fisher CM. 'Transient monocular blindness' versus 'amaurosis fugax'. Neurology 1989;39(12): 1622-4. [PubMed: 2685658]

2. Biousse V, Trobe JD. Transient monocular visual loss. Am J Ophthalmol 2005;140(4):717-21. [PubMed: 16140247]

3. Biousse, V. Cerebrovascular diseases. In: Miller, N.; Newman, N.; Biousse, B.; Kerrison, J., editors. Walsh \& Hoyt's Clinical Neuro-Ophthalmology. 6th edition. Williams \& Wilkins; Philadelphia: 2005. p. 1967-2168.

4. Luneau K, Newman NJ, Biousse V. Ischemic optic neuropathies. Neurologist 2008;14(6):341-54. [PubMed: 19008740]

5. Hayreh SS, Zimmerman MB. Fundus changes in central retinal artery occlusion. Retina 2007;27(3): 276-89. [PubMed: 17460582]

6. Ros MA, Magargal LE, Uram M. Branch retinal-artery obstruction: a review of 201 eyes. Ann Ophthalmol 1989;21(3):103-7. [PubMed: 2735694]

7. Hayreh SS, Podhajsky PA, Zimmerman MB. Branch retinal artery occlusion: natural history of visual outcome. Ophthalmology 2009;116(6):1188-94. e1-4. [PubMed: 19376586]

8. Hayreh SS, Podhajsky PA, Zimmerman MB. Retinal artery occlusion: associated systemic and ophthalmic abnormalities. Ophthalmology 2009;116(10):1928-36. [PubMed: 19577305]

9. Biousse V, Calvetti O, Bruce BB, et al. Thrombolysis for central retinal artery occlusion. J Neuroophthalmol 2007;27(3):215-30. [PubMed: 17895823]

10. Biousse V. Thrombolysis for acute central retinal artery occlusion: is it time? Am J Ophthalmol 2008;146(5):631-4. [PubMed: 18984082]

11. Biousse, V.; Newman, N. Neuro-Ophthalmology Illustrated. Thieme; New York: 2009.

12. Russell RW, Page NG. Critical perfusion of brain and retina. Brain 1983;106(Pt 2):419-34. [PubMed: 6850276]

13. Klijn CJ, Kappelle LJ, van Schooneveld MJ, et al. Venous stasis retinopathy in symptomatic carotid artery occlusion: prevalence, cause, and outcome. Stroke 2002;33(3):695-701. [PubMed: 11872890] 
14. Mendrinos E, Machinis TG, Pournaras CJ. Ocular ischemic syndrome. Surv Ophthalmol 2010;55(1):2-34. [PubMed: 19833366]

15. Mizener JB, Podhajsky P, Hayreh SS. Ocular ischemic syndrome. Ophthalmology 1997;104(5): 859-64. [PubMed: 9160035]

16. Hazin R, Daoud YJ, Khan F. Ocular ischemic syndrome: recent trends in medical management. Curr Opin Ophthalmol 2009;20(6):430-3. [PubMed: 19696669]

17. Biousse V, Touboul PJ, D'Anglejan-Chatillon J, et al. Ophthalmologic manifestations of internal carotid artery dissection. Am J Ophthalmol 1998;126(4):565-77. [PubMed: 9780102]

18. Schievink WI, Mokri B, Garrity JA, et al. Ocular motor nerve palsies in spontaneous dissections of the cervical internal carotid artery. Neurology 1993;43(10):1938-41. [PubMed: 8413949]

19. Lapresle J, Lasjaunias P. Cranial nerve ischaemic arterial syndromes. A review. Brain 1986;109(Pt 1):207-16. [PubMed: 3942855]

20. Hoyt WF. Some neuro-ophthalmological considerations in cerebral vascular insufficiency; carotid and vertebral artery insufficiency. AMA Arch Ophthalmol 1959;62(2):260-72. [PubMed: 13669806]

21. Caplan L. Posterior circulation ischemia: then, now, and tomorrow. The Thomas Willis Lecture-2000. Stroke 2000;31(8):2011-23. [PubMed: 10926972]

22. Devuyst G, Bogousslavsky J, Meuli R, et al. Stroke or transient ischemic attacks with basilar artery stenosis or occlusion: clinical patterns and outcome. Arch Neurol 2002;59(4):567-73. [PubMed: 11939891]

23. Knox DL, Cogan DG. Eye pain and homonymous hemianopia. Am J Ophthalmol Dec;1962 54:1091-3. [PubMed: 14033851]

24. Amarenco P. The spectrum of cerebellar infarctions. Neurology 1991;41(7):973-9. [PubMed: 2067660]

25. Bassetti C, Bogousslavsky J, Barth A, et al. Isolated infarcts of the pons. Neurology 1996;46(1): 165-75. [PubMed: 8559368]

26. Bogousslavsky J, Maeder P, Regli F, et al. Pure midbrain infarction: clinical syndromes, MRI, and etiologic patterns. Neurology 1994;44(11):2032-40. [PubMed: 7969955]

27. Hommel M, Bogousslavsky J. The spectrum of vertical gaze palsy following unilateral brainstem stroke. Neurology 1991;41(8):1229-34. [PubMed: 1866011]

28. Moncayo J, Bogousslavsky J. Vertebro-basilar syndromes causing oculomotor disorders. Curr Opin Neurol 2003;16(1):45-50. [PubMed: 12544856]

29. Vuilleumier P, Bogousslavsky J, Regli F. Infarction of the lower brainstem. Clinical, aetiological and MRI-topographical correlations. Brain 1995;118(Pt 4):1013-25. [PubMed: 7655878]

30. Melson MR, Weyand CM, Newman NJ, et al. The diagnosis of giant cell arteritis. Rev Neurol Dis 2007;4(3):128-42. [PubMed: 17943065]

31. Susac JO. Susac's syndrome: the triad of microangiopathy of the brain and retina with hearing loss in young women. Neurology 1994;44(4):591-3. [PubMed: 8164809]

32. Susac JO, Murtagh FR, Egan RA, et al. MRI findings in Susac's syndrome. Neurology 2003;61(12):1783-7. [PubMed: 14694047]

33. Rennebohm RM, Susac JO. Treatment of Susac's syndrome. J Neurol Sci 2007;257(1-2):215-20. [PubMed: 17324441]

34. Ophoff RA, DeYoung J, Service SK, et al. Hereditary vascular retinopathy, cerebroretinal vasculopathy, and hereditary endotheliopathy with retinopathy, nephropathy, and stroke map to a single locus on chromosome 3p21.1-p21.3. Am J Hum Genet 2001;69(2):447-53. [PubMed: 11438888]

35. Bartynski WS. Posterior reversible encephalopathy syndrome, part 2: controversies surrounding pathophysiology of vasogenic edema. AJNR Am J Neuroradiol 2008;29(6):1043-9. [PubMed: 18403560]

36. Bartynski WS. Posterior reversible encephalopathy syndrome, part 1: fundamental imaging and clinical features. AJNR Am J Neuroradiol 2008;29(6):1036-42. [PubMed: 18356474] 
37. Wong TY, Klein R, Couper DJ, et al. Retinal microvascular abnormalities and incident stroke: the Atherosclerosis Risk in Communities Study. Lancet 2001;358(9288):1134-40. [PubMed: 11597667]

38. Wong TY, Klein R, Sharrett AR, et al. The prevalence and risk factors of retinal microvascular abnormalities in older persons: The Cardiovascular Health Study. Ophthalmology 2003;110(4): 658-66. [PubMed: 12689883]

39. Wang JJ, Mitchell P, Leung H, et al. Hypertensive retinal vessel wall signs in a general older population: the Blue Mountains Eye Study. Hypertension 2003;42(4):534-41. [PubMed: 12939235]

40. Sun C, Wang JJ, Mackey DA, et al. Retinal vascular caliber: systemic, environmental, and genetic associations. Surv Ophthalmol 2009;54(1):74-95. [PubMed: 19171211]

41. Rodriguez-Catarino M, Frisen L, Wikholm G, et al. Internal carotid artery aneurysms, cranial nerve dysfunction and headache: the role of deformation and pulsation. Neuroradiology 2003;45(4):23640. [PubMed: 12687307]

42. Biousse V, Newman NJ. Aneurysms and subarachnoid hemorrhage. Neurosurg Clin N Am 1999;10(4):631-51. [PubMed: 10529975]

43. Newman, SA. Aneurysm. In: Miller, N.; Newman, N.; Biousse, B.; Kerrison, J., editors. Walsh \& Hoyt's Clinical Neuro-Ophthalmology. 6th edition. Williams \& Wilkins; Philadelphia: 2005. p. 2169-262.

44. Miller, N. Carotid-Cavernous Sinus Fistulas. In: Miller, N.; Newman, N.; Biousse, B.; Kerrison, J., editors. Walsh \& Hoyt's Clinical Neuro-Ophthalmology. 6th edition. Williams \& Wilkins; Philadelphia: 2005. p. 2263-96.

45. Kupersmith MJ, Berenstein A, Flamm E, et al. Neuroophthalmologic abnormalities and intravascular therapy of traumatic carotid cavernous fistulas. Ophthalmology 1986;93(7):906-12. [PubMed: 3763135]

46. Biousse V, Newman NJ. Intracranial vascular abnormalities. Ophthalmol Clin North Am 2001;14(1):243-64. [PubMed: 11370570]

47. Qureshi AI, Tuhrim S, Broderick JP, et al. Spontaneous intracerebral hemorrhage. N Engl J Med 2001;344(19):1450-60. [PubMed: 11346811]

48. Singh AD, Rundle PA, Rennie I. Retinal vascular tumors. Ophthalmol Clin North Am 2005;18(1): 167-76. [PubMed: 15763202]

49. Hayreh SS, Zimmerman MB, Podhajsky P. Incidence of various types of retinal vein occlusion and their recurrence and demographic characteristics. Am J Ophthalmol 1994;117(4):429-41. [PubMed: 8154523]

50. Mohamed Q, McIntosh RL, Saw SM, et al. Interventions for central retinal vein occlusion: an evidence-based systematic review. Ophthalmology 2007;114(3):507-19. 24. [PubMed: 17324695]

51. McIntosh RL, Mohamed Q, Saw SM, et al. Interventions for branch retinal vein occlusion: an evidence-based systematic review. Ophthalmology 2007;114(5):835-54. [PubMed: 17397923]

52. Ameri A, Bousser MG. Cerebral venous thrombosis. Neurol Clin 1992;10(1):87-111. [PubMed: 1557011]

53. Ferro JM, Canhao P, Stam J, et al. Prognosis of cerebral vein and dural sinus thrombosis: results of the International Study on Cerebral Vein and Dural Sinus Thrombosis (ISCVT). Stroke 2004;35(3):664-70. [PubMed: 14976332]

54. Biousse V, Ameri A, Bousser MG. Isolated intracranial hypertension as the only sign of cerebral venous thrombosis. Neurology 1999;53(7):1537-42. [PubMed: 10534264]

55. DiNubile MJ. Septic thrombosis of the cavernous sinuses. Arch Neurol 1988;45(5):567-72. [PubMed: 3282499] 


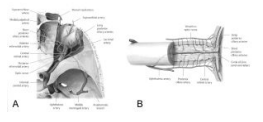

Figure 1. Blood supply to the eye and optic nerve

(A) Superior view of the right orbit showing the internal carotid artery, the ophthalmic artery and its branches in the orbit. (B) Lateral view of the optic nerve showing the arterial blood supply of the optic nerve via very small branches of the ophthalmic artery (posterior ciliary artery). Reprinted with permission from Biousse V, Newman NJ. Neuro-Ophthalmology Illustrated. Thieme, 2009. 

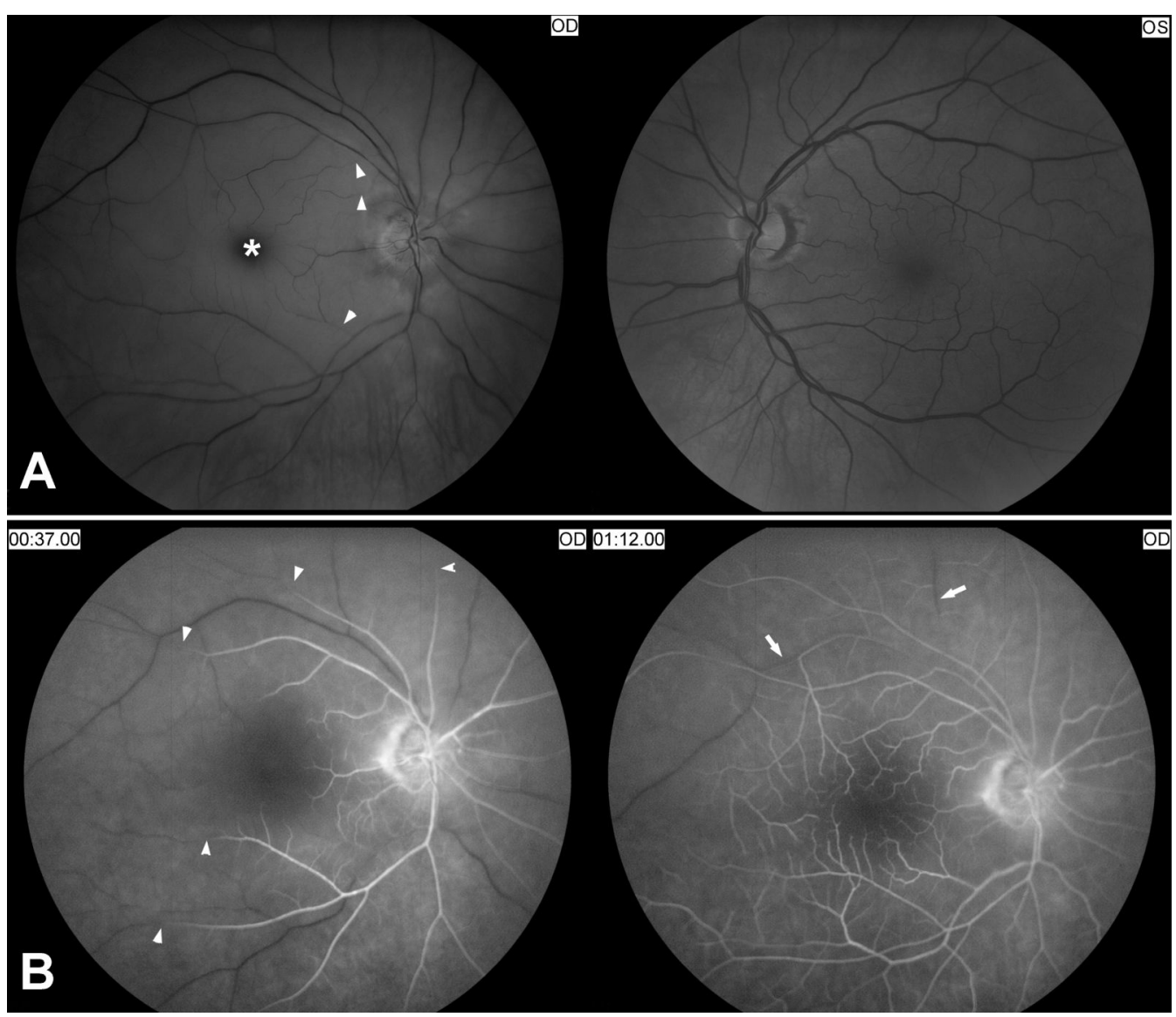

Figure 2. Acute central retinal artery occlusion in the right eye

A) Funduscopic photographs showing an acute central retinal artery occlusion in the right eye (OD, shown on the left). Note the attenuated central retinal artery with segmental arterial narrowing in the right eye (arrow heads) compared with the left eye (OS, shown on the right). The ischemic retina is edematous and appears whitish compared to the left eye and there is a cherry red spot $(*)$.

B) Fluorescein angiography of the right eye (OD) at 37seconds after injection of fluorescein dye in an arm vein (shown on the left), and at more than 1 minute (shown on the right). There is delayed retinal arterial filling (arrow heads). Venous filling (arrows) is also delayed at more than 1 minute. 


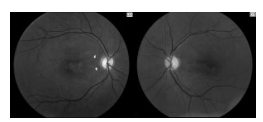

Figure 3. Right optic atrophy secondary to an old central retinal artery occlusion Funduscopic photograph showing an old central retinal artery occlusion in the right eye (OD, shown on the left). Note the optic disc pallor with narrowing and sheathing of some arterioles in the right eye (arrow heads) compared with the left eye (OS, shown on the right). 

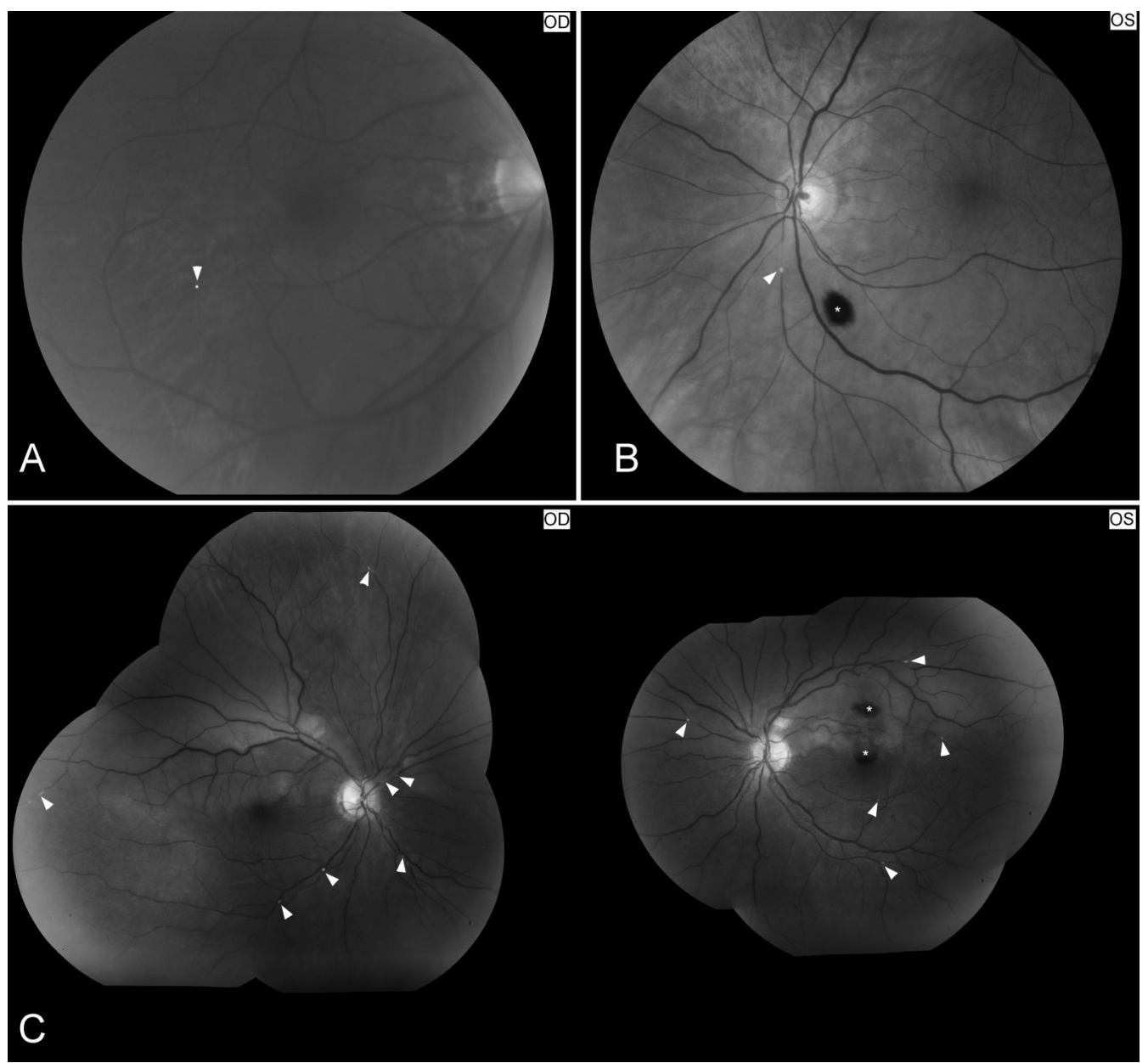

Figure 4. Examples of retinal artery emboli

Funduscopic photographs showing: (A) a refractile cholesterol retinal embolus (Hollenhorst plaque, arrow head) found in the right eye of a patient who had an episode of transient visual loss in the right eye (OD); (B) a branch retinal artery embolus in a patient with monocular vision loss in the left eye (OS). The embolus is whitish and disrupts the blood flow within the artery, suggesting a platelet-fibrin embolus (arrow head) from carotid artery atheroma. There is an intraretinal hemorrhage inferiorly related to retinal ischemia (*); (C) multiple bilateral retinal emboli (arrow heads) in the setting of valvular endocarditis (Roth's spots) with bilateral branch arterial occlusions and two intraretinal hemorrhages OS (*). 


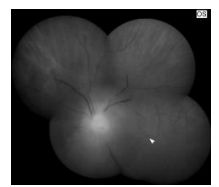

Figure 5. Left ophthalmic artery occlusion

Funduscopic photograph showing a severe left ophthalmic artery occlusion with massive retinal ischemia and ischemic disc edema. The arteries are barely visible and there is no cherry red spot (arrow head). 


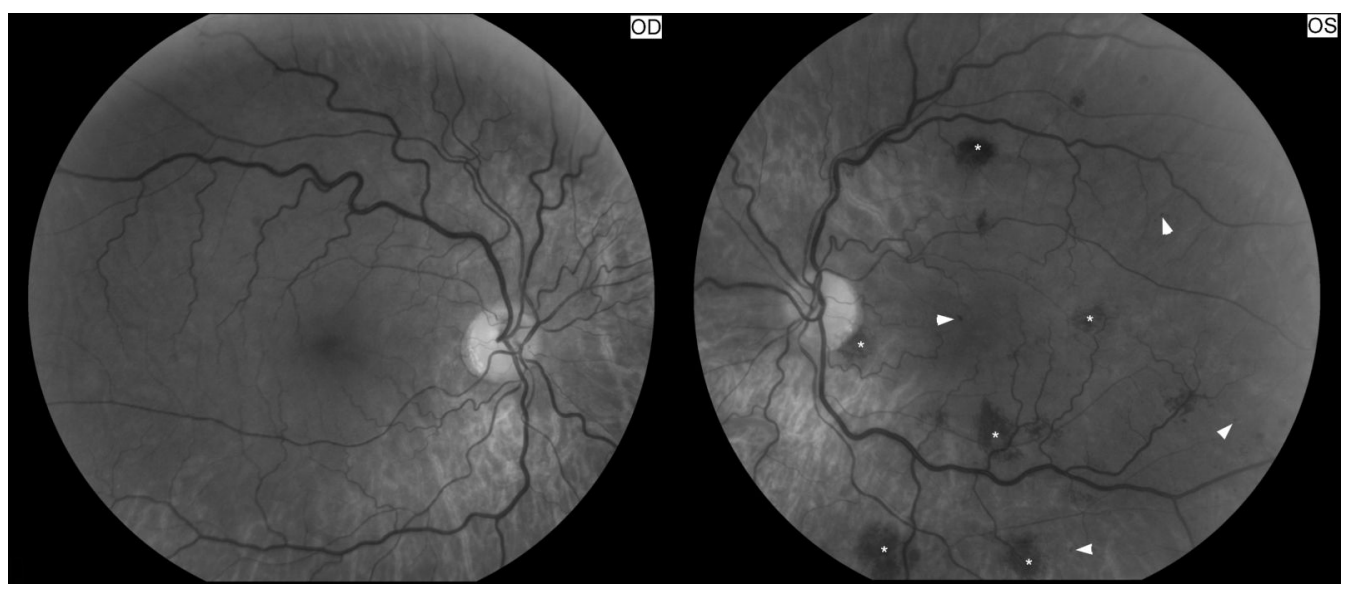

Figure 6. Left venous stasis retinopathy

Funduscopic photograph showing venous stasis retinopathy in the left eye (OS, shown on the right) secondary to a left internal carotid artery occlusion. Note the multiple retinal hemorrhages $(*)$, with microaneurysms (arrow heads). 

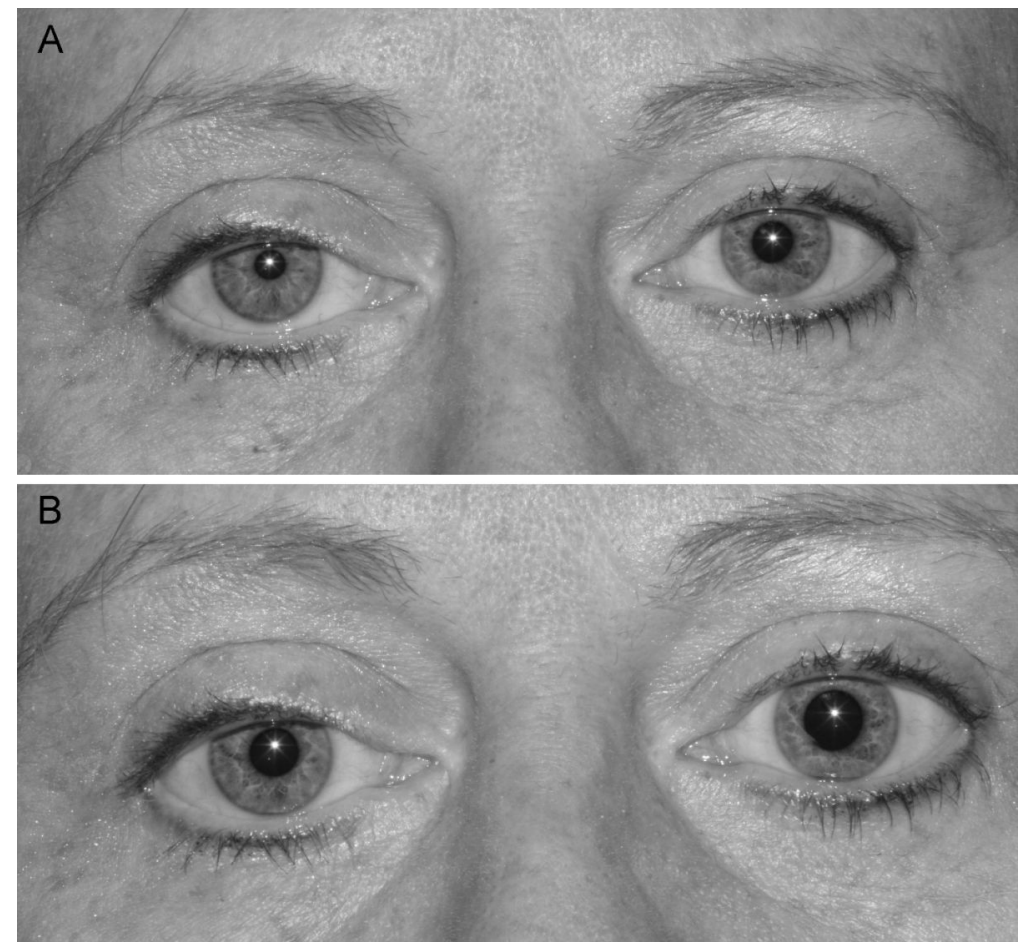

Figure 7. Right Horner syndrome related to a right internal carotid artery occlusion There is mild right upper lid ptosis and anisocoria with the right pupil being smaller than the left pupil in the light (A) and in the dark (B). The anisocoria is greater in the dark than in the light and there was dilation lag of the right pupil in the dark. 


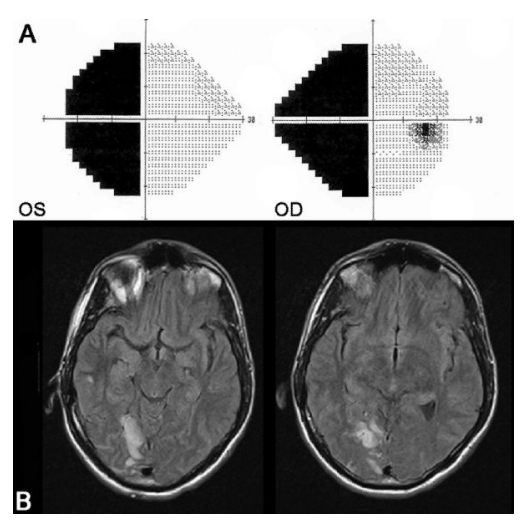

Figure 8. Left homonymous hemianopia secondary to a right occipital infarction

(A) 24-2 Humphrey visual fields showing a complete left homonymous hemianopia (the right eye visual field is on the right and the left eye visual field is on the left. (B) FLAIR axial brain MRI demonstrates a right occipital infarction in the territory of the right posterior cerebral artery. 

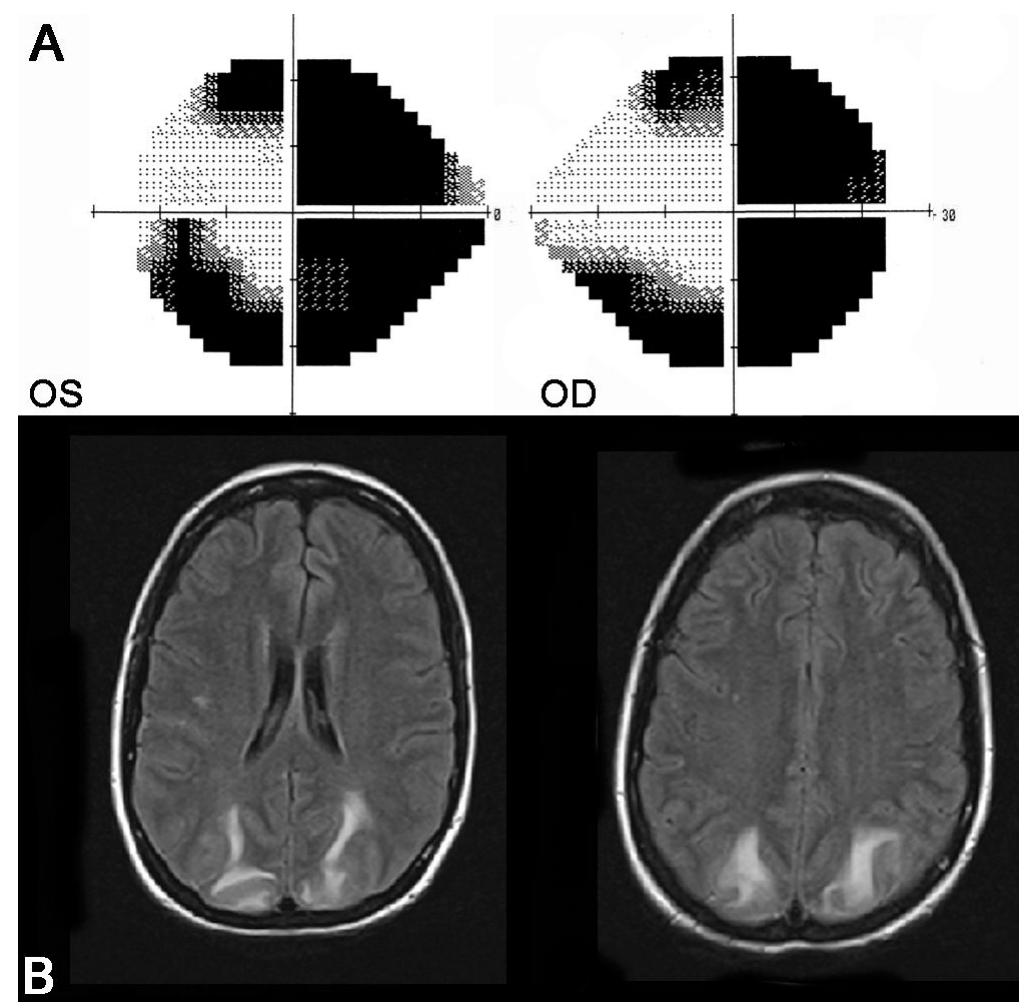

Figure 9. Bilateral homonymous hemianopia related to posterior reversible encephalopathy syndrome

(A) 24-2 Humphrey visual fields showing a complete right homonymous hemianopia and an incomplete congruous left homonymous hemianopia. This patient had malignant hypertension and the FLAIR axial brain MRI (B) showed bilateral occipital lesions suggesting posterior reversible encephalopathy syndrome (PRES). The visual field defects resolved after treatment of the hypertension and the brain MRI normalized within two weeks. 


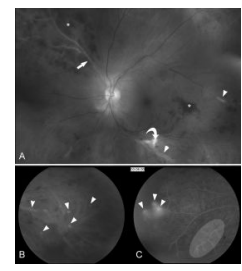

Figure 10. Retinal vasculitis

(A) Funduscopic photograph of the left eye showing extensive vasculitis with periarterial sheathing (arrow heads), a branch retinal artery occlusion (arrow), and retinal ischemia; note the cotton-wool spots (curved arrow) and intraretinal hemorrhages (*). (B) Magnification of the same photograph showing the periarterial sheating (arrow heads). (C) Fluorescein angiogram (at 3 minutes and 8 seconds) showing arterial leakage (arrow heads) and the very attenuated arterial vasculature (white ellipse). 

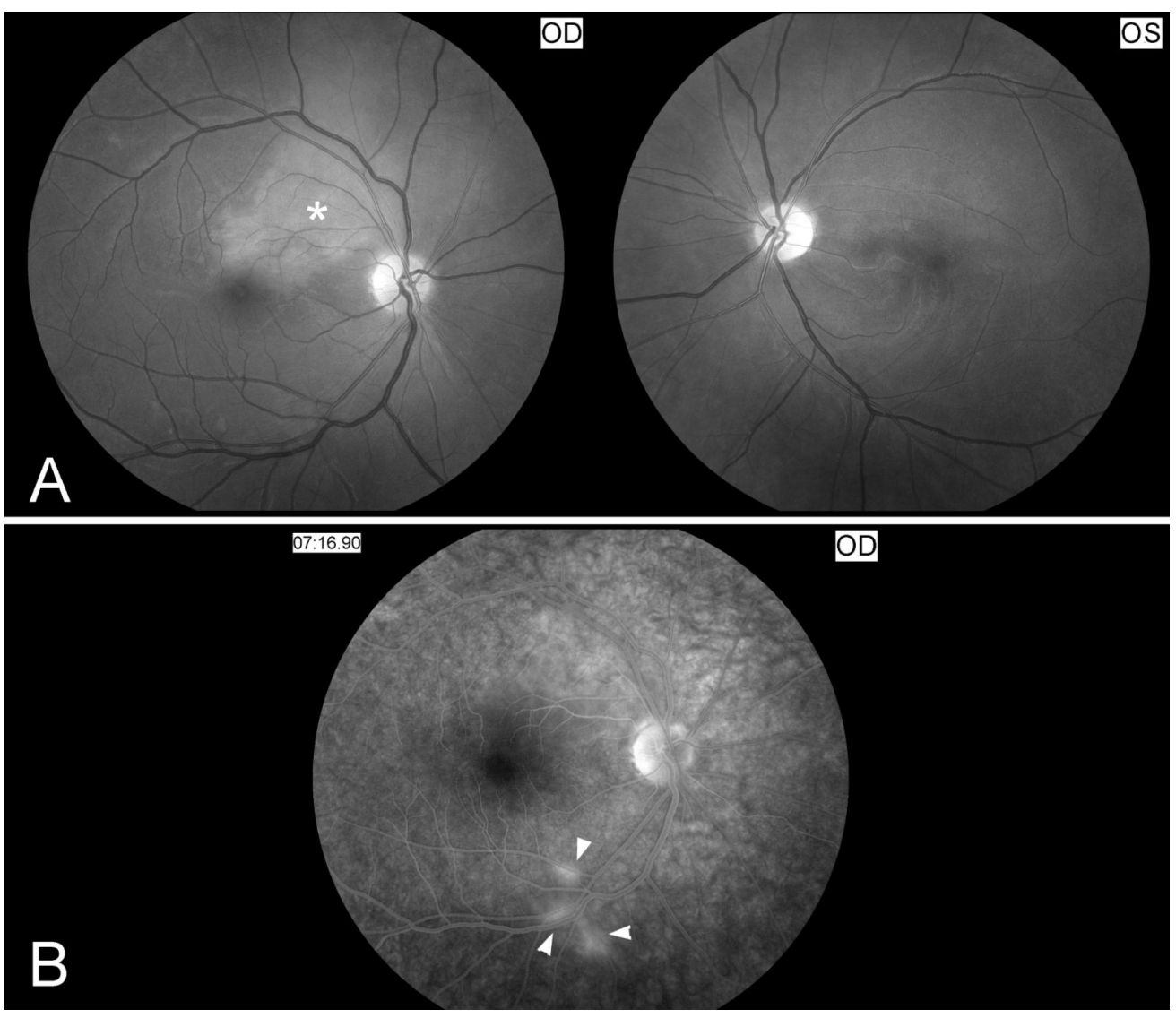

Figure 11. Funduscopic and fluorescein angiographic findings in Susac syndrome

(A) Funduscopic photograph of a young woman with recurrent bilateral branch retinal artery occlusions related to Susac syndrome. There is an area of ischemia superiorly (*) in the right eye (OD, shown on the left). In the left eye (OS, shown on the right) there is diffuse arterial attenuation and optic disc pallor from prior arterial occlusions. (B) Fluorescein angiogram of the right eye showing 3 areas of arterial leakage distant from the ischemic retina (arrow heads), highly suggestive of Susac syndrome. 


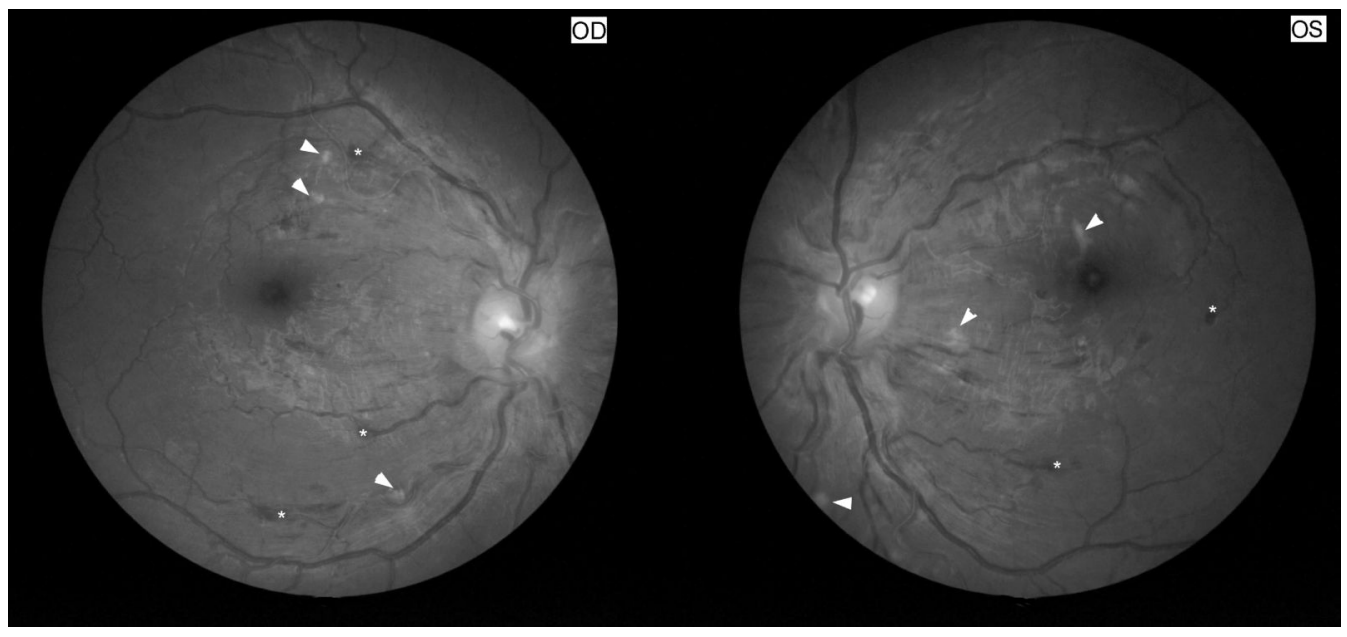

Figure 12. Hypertensive retinopathy stage IV

Funduscopic photographs showing severe bilateral retinal changes with disc edema suggesting hypertensive retinopathy stage IV. Note the bilateral optic nerve head edema, cotton wool spots (arrow heads) and superficial retinal hemorrhages (*). Blood pressure was 200/130 mmHg. 


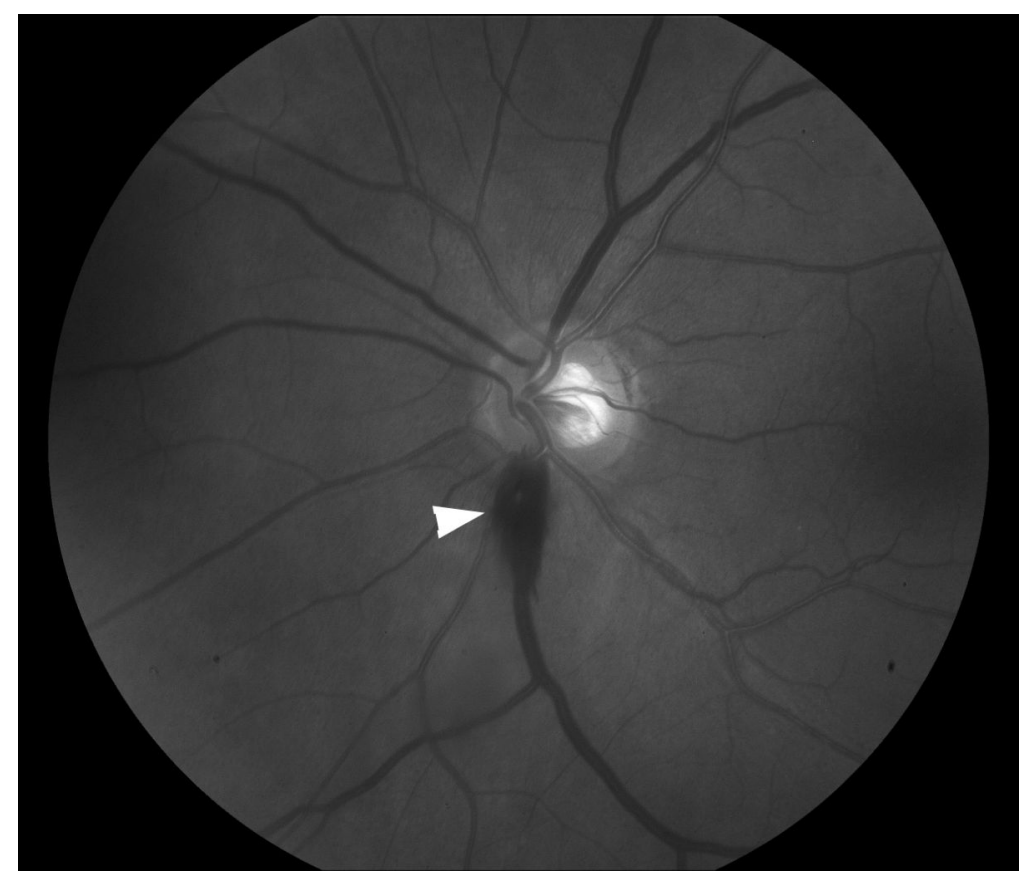

Figure 13. Left Terson syndrome

Funduscopic photograph showing a preretinal hemorrhage inferior to the optic nerve (arrow head) in a patient with subarachnoid hemorrhage, consistent with Terson syndrome. 


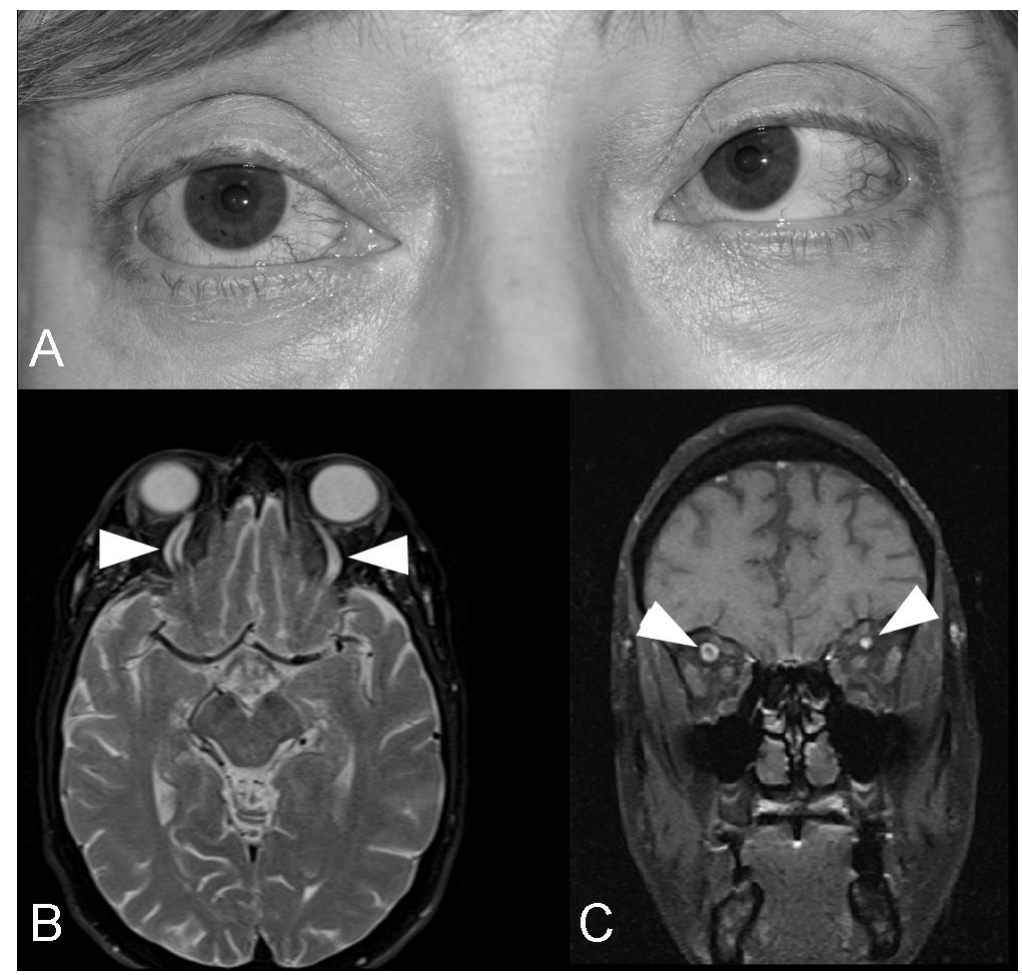

Figure 14. Indirect dural carotid cavernous fistula with bilateral sixth nerve palsies (A) External photograph of a 55 year old woman with bilateral sixth nerve palsies with esotropia, and dilation of the episcleral vessels in both eyes. T2-axial brain MRI through the upper part of the orbits (B) and T1-coronal orbital MRI with contrast and fat suppression showing dilation of both superior ophthalmic veins (arrow heads). A catheter angiogram showed a complex indirect dural carotid cavernous fistula draining mostly posteriorly. 


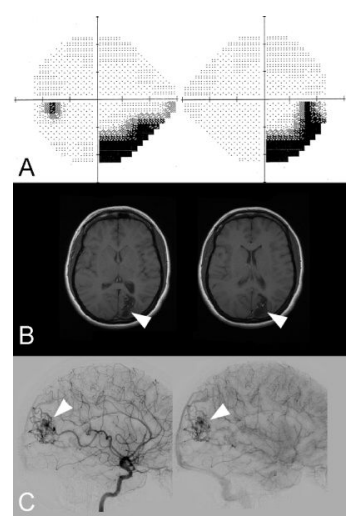

Figure 15. Right homonymous hemianopia related to a left occipital arteriovenous malformation (A) 24-2 Humphrey visual fields showing an incomplete congruous right homonymous hemianopia. (B) Brain MRI showed a heterogeneous and irregular hyposignal in the left occipital lobe on the axial-T1-weighted image. (C) Catheter cerebral angiogram confirmed a left occipital arteriovenous malformation. 


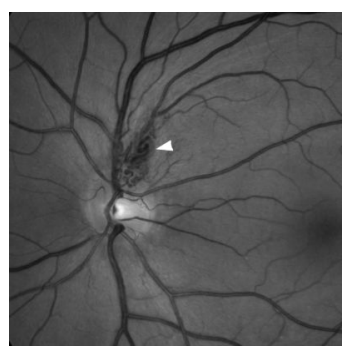

Figure 16. Retinal cavernous hemangioma

Funduscopic photograph showing a small retinal cavernous hemangioma superior to the optic nerve in the left eye. 


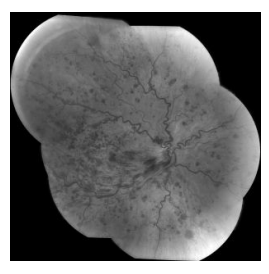

Figure 17. Right central retinal vein occlusion

Funduscopic photograph showing a right central retinal vein occlusion with dilation and tortuosity of the veins, multiple retinal hemorrhages, and disc edema. 


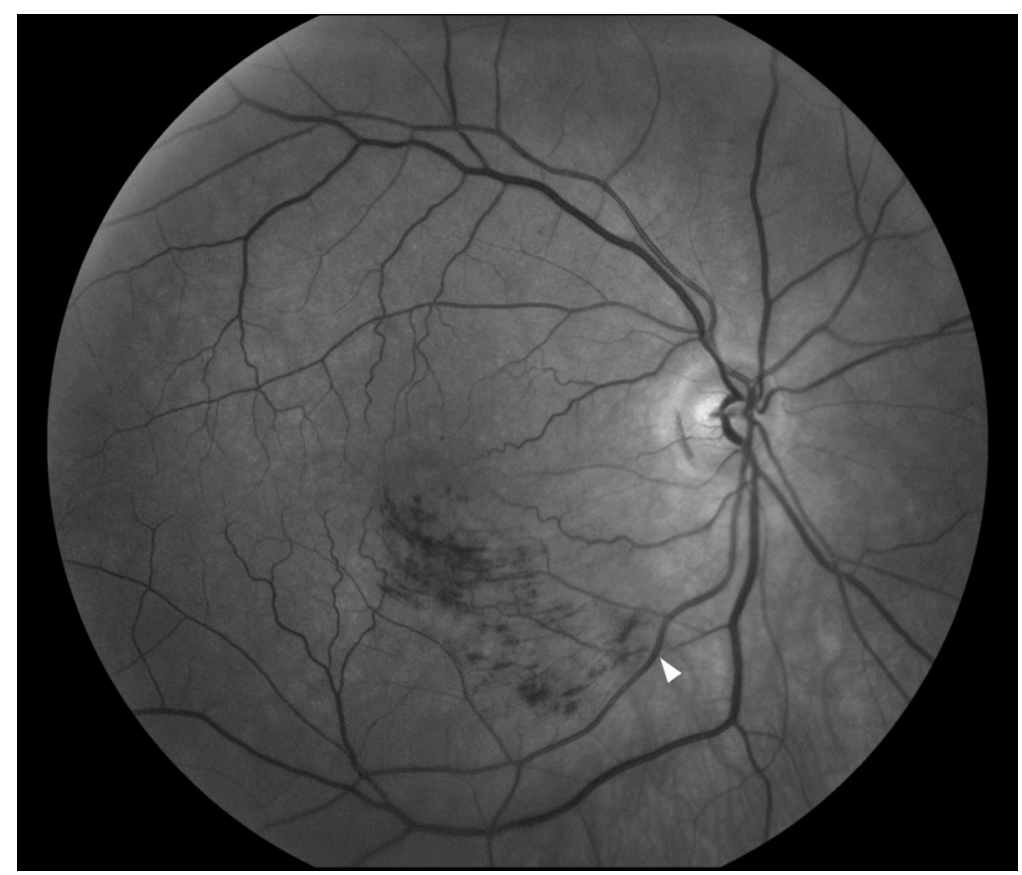

Figure 18. Branch retinal vein occlusion

Funduscopic photograph showing an inferior temporal branch retinal vein occlusion in the right eye. The vein is occluded by the artery at an arteriovenous crossing (arrow head). The area of superficial retinal hemorrhages is limited to the territory drained by the occluded vein. 


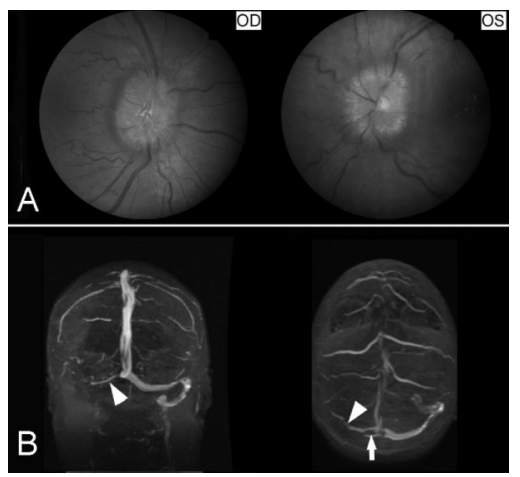

Figure 19. Cerebral venous thrombosis

(A) Fundus photographs showing bilateral prominent papilledema from raised intracranial pressure. (B) Brain MRV (coronal shown on the left and axial shown on the right) showing occlusion of the right transverse sinus and right sigmoid sinus (arrow heads). 
Table 1

Most common types of retinal emboli.

\begin{tabular}{llll}
\hline Type of retinal emboli & Source of emboli & Funduscopic appearance & Location in the retina \\
\hline $\begin{array}{l}\text { Cholesterol } \\
\text { (Hollenhorst plaque) }\end{array}$ & $\begin{array}{l}\text { Ipsilateral internal carotid artery } \\
\text { Aortic arch }\end{array}$ & $\begin{array}{l}\text { Yellow, refractile } \\
\text { Multiple in 70\% of cases } \\
\text { Appear wider than the arteriole }\end{array}$ & Often at an arteriole bifurcation \\
\hline Platelet-fibrin & $\begin{array}{l}\text { Carotid thrombus } \\
\text { Aortic arch thrombus } \\
\text { Cardiac thrombus } \\
\text { Cardiac prosthesis } \\
\text { Calcified atheromatous plaque or } \\
\text { cardiac valve }\end{array}$ & $\begin{array}{l}\text { White-grey, pale, not refractile } \\
\text { Often multiple }\end{array}$ & Within small retinal arterioles \\
\hline Infectious & $\begin{array}{l}\text { Bacterial endocarditis } \\
\text { Candidemia }\end{array}$ & $\begin{array}{l}\text { Usually isolated } \\
\text { White spots (Roth's spots) } \\
\text { Multiple }\end{array}$ & No specific pattern \\
\hline Fat & Fat emboli in the setting of leg facture & $\begin{array}{l}\text { Whitish spots with hemorrhages } \\
\text { and cotton wool spots } \\
\text { Multiple }\end{array}$ & No specific pattern \\
\hline Neoplasm & Cardiac myxoma & $\begin{array}{l}\text { White, grey } \\
\text { Often Multiple }\end{array}$ & In the proximal segment of the central \\
Talc & Intravenous drugs & $\begin{array}{l}\text { Yellow, refractile } \\
\text { Multiple }\end{array}$ & No specific pattern \\
\hline
\end{tabular}


Table 2

Common causes of cerebral visual loss classified by mechanism.

\begin{tabular}{|c|c|}
\hline Mechanism & Cause of vision loss \\
\hline Vascular & $\begin{array}{l}\text { Vertebrobasilar ischemia (posterior cerebral artery territory) } \\
\text { Cerebral anoxia } \\
\text { Cerebral venous thrombosis (superior sagittal sinus) } \\
\text { Hypertensive encephalopathy (Posterior Reversible Encephalopathy Syndrome) } \\
\text { Eclampsia }\end{array}$ \\
\hline Head trauma & Occipital lobe injury \\
\hline Occipital mass & $\begin{array}{l}\text { Tumor } \\
\text { Abscess } \\
\text { Vascular (aneurysm, arteriovenous malformation) } \\
\text { Hemorrhage }\end{array}$ \\
\hline Demyelinating disease & Multiple Sclerosis \\
\hline Infection & $\begin{array}{l}\text { Occipital abscess } \\
\text { Meningitis } \\
\text { Progressive multifocal leucoencephalopathy } \\
\text { Creutzfeld-Jacob disease }\end{array}$ \\
\hline Toxic & $\begin{array}{l}\text { Cyclosporine } \\
\text { Tacrolimus }\end{array}$ \\
\hline Metabolic & $\begin{array}{l}\text { Hypoglycemia } \\
\text { Porphyria } \\
\text { Hepatic encephalopathy }\end{array}$ \\
\hline Migraine & Migrainous visual aura \\
\hline Seizure & Occipital lobe seizures \\
\hline Degenerative & Alzheimer disease / posterior cortical atrophy \\
\hline
\end{tabular}




\section{Table 3}

Characteristics of the three autosomal dominant cerebro-ocular vasculopathies mapped to chromosome 3 .

\begin{tabular}{|c|c|c|c|}
\hline Name & Ocular findings & Neurologic findings & Other findings \\
\hline $\begin{array}{l}\text { Hereditary Vascular Retinopathy } \\
\text { (HVR) }\end{array}$ & $\begin{array}{l}\text { Microangiopathy } \\
\text { Retinal periphery and posterior pole }\end{array}$ & $\begin{array}{l}\text { Multiple small lesions in GM and WM } \\
\text { Headaches }\end{array}$ & Raynaud phenomenon \\
\hline $\begin{array}{l}\text { Cerebro-Retinal Vasculopathy } \\
\text { (CRV) }\end{array}$ & $\begin{array}{l}\text { Microangiopathy } \\
\text { Posterior pole }\end{array}$ & $\begin{array}{l}\text { Cerebral pseudotumors } \\
\text { Extensive WM lesions } \\
\text { Dementia } \\
\text { Headaches } \\
\text { Death }<55 \text { years }\end{array}$ & \\
\hline $\begin{array}{l}\text { Hereditary Endotheliopathy, } \\
\text { Retinopathy, Nephropathy and } \\
\text { Stroke } \\
\text { (HERNS) }\end{array}$ & $\begin{array}{l}\text { Microangiopahty } \\
\text { Posterior pole }\end{array}$ & $\begin{array}{l}\text { Cerebral pseudotumors } \\
\text { Extensive WM lesions } \\
\text { Dementia } \\
\text { Headaches } \\
\text { Stroke } \\
\text { Death <55 years }\end{array}$ & Renal involvement \\
\hline
\end{tabular}

WM: white matter, GM: grey matter. 
Table 4

Miscellanous angiopathies of the central nervous system with ocular manifestations.

\begin{tabular}{|c|c|c|c|}
\hline Disease & Ocular manifestations & Mechanism of angiopathy & Transmission \\
\hline Neurofibromatosis I & $\begin{array}{l}\text { Neurofibromas, iris Lish } \\
\text { nodules, optic nerve } \\
\text { gliomas, retinal hamartomas }\end{array}$ & $\begin{array}{l}\text { Arterial dissections, aneurysms, fistulae } \\
\text { ganglioneuromas, neurofibromas }\end{array}$ & Autosomal dominant \\
\hline von Hippel-Lindau syndrome & Retinal angiomas & $\begin{array}{l}\text { Cerebellar, brainstem, and spinal cord } \\
\text { hemangioblastoma }\end{array}$ & Autosomal dominant \\
\hline $\begin{array}{l}\text { Tuberous sclerosis (Bourneville } \\
\text { disease) }\end{array}$ & Retinal hamartomas & Intracranial aneurysms, moyamoya syndrome & Autosomal dominant \\
\hline $\begin{array}{l}\text { Rendu-Osler-Weber syndrome } \\
\text { (hereditary hemorrhagic } \\
\text { telangiectasia) }\end{array}$ & Retinal telangiectasia & $\begin{array}{l}\text { Arteriovenous malformations, venous } \\
\text { angiomas, } \\
\text { aneurysms, meningeal telangiectasia }\end{array}$ & Autosomal dominant \\
\hline $\begin{array}{l}\text { Sturge-Weber syndrome } \\
\text { (encephalofacial angiomatosis) }\end{array}$ & $\begin{array}{l}\text { Skin, conjunctiva, episclera, } \\
\text { uveal angiomas; glaucoma }\end{array}$ & $\begin{array}{l}\text { Leptomeningeal venous angioma, } \\
\text { arteriovenous } \\
\text { malformations, venous and dural sinus } \\
\text { abnormalities }\end{array}$ & $\begin{array}{l}\text { Possibly autosomal } \\
\text { dominant } \\
\text { Mostly sporadic }\end{array}$ \\
\hline $\begin{array}{l}\text { Wyburn-Mason syndrome } \\
\text { (Racemose angioma) }\end{array}$ & $\begin{array}{l}\text { Retinal arteriovenous } \\
\text { malformations }\end{array}$ & $\begin{array}{l}\text { Cerebral arteriovenous malformations (usually } \\
\text { brainstem) }\end{array}$ & Sporadic \\
\hline $\begin{array}{l}\text { Ataxia-telangiectasia (Louis-Bar } \\
\text { syndrome) }\end{array}$ & $\begin{array}{l}\text { Oculocutaneous } \\
\text { telangiectasia }\end{array}$ & Telangiectasia & Autosomal recessive \\
\hline Marfan syndrome & $\begin{array}{l}\text { Lens subluxation, retinal } \\
\text { detachment }\end{array}$ & Aneurysms, aortic dissection & Autosomal dominant \\
\hline Fibromuscular dysplasia & Retinal emboli & $\begin{array}{l}\text { Arterial stenosis, arterial dissections } \\
\text { aneurysms, } \\
\text { carotid cavernous fistula }\end{array}$ & $\begin{array}{l}\text { Possibly autosomal } \\
\text { dominant } \\
\text { Mostly sporadic }\end{array}$ \\
\hline Ehler-Danlos syndrome (type IV) & $\begin{array}{l}\text { Ocular ischemia, angioid } \\
\text { streaks }\end{array}$ & $\begin{array}{l}\text { Aneurysms, carotid cavernous fistula carotid } \\
\text { or } \\
\text { vertebral artery dissection }\end{array}$ & Heterogeneous \\
\hline $\begin{array}{l}\text { Pseudoxanthoma elasticum } \\
\text { (Gronblad-Strandberg } \\
\text { syndrome) }\end{array}$ & $\begin{array}{l}\text { Angioid streaks, peau } \\
\text { d'orange fundus }\end{array}$ & $\begin{array}{l}\text { Premature atherosclerosis, aneurysms, carotid } \\
\text { cavernous fistula }\end{array}$ & Heterogenous \\
\hline Moyamoya syndrome & $\begin{array}{l}\text { Morning glory disc, ocular } \\
\text { ischemia }\end{array}$ & $\begin{array}{l}\text { Nonintlammatory occlusive intra-cranial } \\
\text { vasculopathy. }\end{array}$ & $\begin{array}{l}\text { May be associated } \\
\text { with other } \\
\text { hereditary disorders }\end{array}$ \\
\hline $\begin{array}{l}\text { Menkes syndrome (Kinky hair } \\
\text { disease) }\end{array}$ & Ocular ischemia & $\begin{array}{l}\text { Tortuosity, elongation and occlusion of } \\
\text { cerebral } \\
\text { arteries }\end{array}$ & $\mathrm{X}$-Linked recessive \\
\hline $\begin{array}{l}\text { Fabry disease (angiokeratoma } \\
\text { corporis diffusum) }\end{array}$ & $\begin{array}{l}\text { Whorl-like corneal } \\
\text { opacification, tortuosity of } \\
\text { vessels }\end{array}$ & $\begin{array}{l}\text { Glycosphingolipid deposit in endothelial cells, } \\
\text { cerebral aneurysms }\end{array}$ & $\mathrm{X}$-Linked recessive \\
\hline $\begin{array}{l}\text { Homocystinuria and } \\
\text { homocysteinemia }\end{array}$ & $\begin{array}{l}\text { Retinal ischemia, lens } \\
\text { subluxation }\end{array}$ & $\begin{array}{l}\text { Premature atherosclerotic occlusion of carotid } \\
\text { arteries and large cerebral arteries }\end{array}$ & Autosomal recessive \\
\hline $\begin{array}{l}\text { CADASIL (cerebral autosomal } \\
\text { dominant arteriopathy with } \\
\text { subcortical infarcts and } \\
\text { leukoencephalopathy) }\end{array}$ & Valcular retinopathy & $\begin{array}{l}\text { Non atherosclerotic, nonamyloidotic } \\
\text { angiopathy of } \\
\text { leptomeningeal and small penetrating arteries }\end{array}$ & Autosomal dominant \\
\hline $\begin{array}{l}\text { MELAS (mitochondrial } \\
\text { myopathy, encephalopathy, } \\
\text { lactic acidosis, stroke-like } \\
\text { episodes) }\end{array}$ & $\begin{array}{l}\text { Optic atrophy, chronic } \\
\text { progressive external } \\
\text { ophthalmoplegia, } \\
\text { pigmentary retinopathy }\end{array}$ & $\begin{array}{l}\text { Proliferation of mitochondria in smooth } \\
\text { muscle cells } \\
\text { of cerebral vessels }\end{array}$ & $\begin{array}{l}\text { Maternally inherited } \\
\text { (point } \\
\text { mutation in } \\
\text { mitochondrial } \\
\text { DNA) }\end{array}$ \\
\hline
\end{tabular}

